\title{
INDIGENOUS KNOWLEDGE AS A KEY TO SUSTAINABLE DEVELOPMENT
}

\author{
S.G.J.N. Senanayake ${ }^{1}$
}

\begin{abstract}
Indigenous knowledge is the unique knowledge confined to a particular culture or society. It is also known as local knowledge, folk knowledge, people's knowledge, traditional wisdom or traditional science. This knowledge is generated and transmitted by communities, over time, in an effort to cope with their own agroecological and socio-economic environments (Fernandez, 1994). It is generated through a systematic process of observing local conditions, experimenting with solutions and readapting previously identified solutions to modified environmental, socio-economic and technological situations (Brouwers, 1993). Indigenous knowledge is passed from generation to generation, usually by word of mouth and cultural rituals, and has been the basis for agriculture, food preparation and conservation, health care, education, and the wide range of other activities that sustain a society and its environment in many parts of the world for many centuries.
\end{abstract}

Key Words: Indigenous knowledge, local Knowledge, Folk knowledge, Traditional wisdom, Traditional Science.

\section{INTRODUCTION}

Indigenous knowledge is considered as the social capital of the poor. It is their main asset to invest in the struggle for survival, to produce food, to provide for shelter and to achieve control of their own lives. Most of the indigenous knowledge disappears due to the intrusion of foreign technologies and development concepts that promise short-term gains or solutions to problems without being capable of sustaining them. The tragedy of the disappearance of this knowledge system is most obvious to those who have developed it and make a living through it. But the implication for others can be detrimental as well, when skills, technologies, artifacts, problem solving strategies and expertise are lost.

Most authors (Flavier, 1995; Grenier, 1998 and Mathias, 1995) have explained their perception of indigenous knowledge covering only some aspects of it. In contrast, Ellen and Harris (1996) have provided following ten characteristics of indigenous knowledge that are very comprehensive and conclusive.

1. Indigenous knowledge is local. It is rooted to a particular place and set of experiences, and generated by people living in those places. The result of this is that transferring the indegenous knowledge to other places runs the risk of dis-locating it.

2. Indigenous knowledge is orally-transmitted, or transmitted through imitation and demonstration. The consequence is that writing it down changes some of its fundamental properties. Writing, of course, also makes it more portable and permanent, reinforcing the dislocation referred to in 1 . 
3. Indigenous knowledge is the consequence of practical engagement in everyday life, and is constantly reinforced by experience and trial and error. This experience is characteristically the product of many generations of intelligent reasoning, and since its failure has immediate consequences for the lives of its practitioners its success is very often a good measure of Darwinian fitness. It is tested in the rigorous laboratory of survival.

4. 1 and 3 support a further general observation, that it is empirical rather than theoretical knowledge. To some extent, its oral character hinders the kind of organization necessary for the development of true theoretical knowledge.

5. Repetition is an essential characteristic of tradition, even when new knowledge is added. Repetition aids retention and reinforces ideas; it is also partly a consequence of 1 and 2 .

6. Tradition could be considered as 'a fluid and transforming agent with no real end' when applied to knowledge and it's central concept is negotiation. Indigenous knowledge is, therefore, constantly changing, being produced as well as reproduced, discovered as well as lost; though it is often represented as being somehow static.
7. Indigenous knowledge is characteristically shared to a much greater degree than other forms of knowledge. Therefore, it is sometimes called 'people's science'. However, its distribution is still segmentary and socially clustered. It is usually asymmetrically distributed within a population, by gender and age and preserved through distribution in the memories of different individuals. Specialists may exist by virtue of experience.

8. Although indigenous knowledge may be focused on particular individuals and may achieve a degree of coherence in rituals and other symbolic constructs, its distribution is always fragmentary. Generally it does not exist in its totality in any one place or individual. It is devolved in the practices and interactions in which people themselves engage.

9. Despite claims for the existence of culture-wide (indeed universal) abstract classifications of knowledge based on non-functional criteria; where indigenous knowledge is at its densest and directly applicable its organization is essentially functional.

10. Indigenous knowledge is characteristically situated within broader cultural traditions; separating the technical from the nontechnical, the rational from the non-rational is problematic. 
Indigenous knowledge systems have a broad perspective of the ecosystems and of sustainable ways of using natural resources. However, colonial education system replaced the practical everyday life aspects of indigenous knowledge and ways of learning with Western ideas of theoretical knowledge and academic ways of learning. Today, there is a grave risk that much indigenous knowledge is being lost and, along with it, valuable knowledge about ways of living sustainably both ecologically and socially. The role of nineteenth century colonialism in ignoring and sometimes maligning indigenous knowledge of Sri Lanka as well as of other colonial countries has been well documented by various workers (Slikkerveer, 1989 and Warren, 1989). As a result of the impact of nineteenth century social science in establishing negative values and attitudes towards indigenous knowledge systems (Warren, 1989), even during early post colonial period, many scientists and academics considered indigenous knowledge systems as primitive, simple and static. Therefore indigenous knowledge systems have not been systematically recorded in written form and are not readily accessible to agricultural researchers, development practitioners, and policy makers. Recently some workers have shown the interest on indigenous knowledge and they have provided a detailed overview (Warren, 1991), and a general explanation of indigenous knowledge, with a particular emphasis on genetic resources, pastoral management and agro forestry (Rajasekaran, et al 1991), and offered a more succinct discussion (Warren and Rajasekaran 1993). However, still there is a grave risk that much indigenous knowledge is being lost and, along with it, valuable knowledge about ways of living sustainably both ecologically and socially. Therefore the objectives of this paper are to illustrate the potential of indigenous knowledge in sustainable development process and encourage academics, policy makers, scientists and students to gain enhanced respect for local culture, its wisdom and its environmental ethics.

\section{DISCUSSION}

\section{Indigenous Knowledge and Cultural Diversity}

A closer look at the local traditions in a country reveals the methods by which the cultural and ecological balance is maintained. Culture is defined by the ecological conditions and the traditional institutions that help to sustain the community (Mishra, 1994). This promotes a situation of "constructive dependence" instead of "destructive dependence" of so called modern development. Evidence of this is found in various myths, taboos, rules and regulations that form part of the local culture and ethos.

The generation, adaptation and use of indigenous knowledge are greatly influenced by the culture. Economic, social, political and geographical contexts also contribute to generate indigenous knowledge, but to a lesser extent. Therefore, indigenous knowledge systems show great diversity not only among ethnic groups but among locations also. There are at least four ways to understand and compare the indigenous knowledge systems in different cultures.

- A different knowledge of similar things;

- A different knowledge of different things

- Different ways of organizing knowledge and 
- Different ways of preserving and transferring knowledge.

\section{Indigenous Knowledge and Biological Diversity}

Biological diversity is now threatened by extinction. According to Quiroz (1996), biological diversity and cultural diversity are two sides of the same coin. Living diversity in nature corresponds to a living diversity of cultures. With cultural and environmental changes, both biodiversity and the indigenous knowledge systems vital to sustainability are being lost at an incredible rate (Haverkort and Millar, 1994). Poverty is one of the main reasons for this rapid loss of biodiversity and indigenous knowledge systems. Poverty increases the pressure on natural resources and diverts people from complex indigenous knowledge systems to simple and easy techniques such as chemical agriculture. In addition, introduction of "modern" commercial agricultural technology from West displaces or even eliminates the local practices (indigenous knowledge) in favour of modern practices such as mono-cropping (simplification of ecosystems for socalled easy and "efficient" practices). This has led to the degradation of natural resources, poorer nutrition and loss of informal channels of communication (Shiva, 1993). Appleton (1993) and Larson (1998) have provided examples of the loss of indigenous knowledge systems through the loss of indigenous channels of communication.

The author of this paper compared the knowledge which a 26 year old young farmer from Buttala (rural area of Sri Lanka) had of traditional practices with that of his grand farther (a farmer at age of 82 years) and found that younger farmer's knowledge was very much reduced. It is widely accepted that traditional farmers conserve the biodiversity as they are the practitioners of environmental processes designed to transform, manage and use the nature. Therefore, the indigenous knowledge accumulated by these people constitutes a pool of techniques which are of great importance for long-term sustainability.

\section{Use of Indigenous Knowledge in Sustainable Development Process}

All most all the development actors have now recognized the value of participatory approaches in decisionmaking for sustainable development. Indigenous knowledge provides the basis for grassroots decision-making. It is recently found that the indigenous knowledge of ecological zones, natural resources, agriculture, aquaculture, forest and game management is far more sophisticated than previously assumed (Posey, 1995). Furthermore, this knowledge offers new models for development that are both ecologically and socially sound. Therefore, it is a well known fact that development activities that work with and through indigenous knowledge have several important advantages over projects that operate outside them. One classic example is that reverting back to "nonscientific" polyculture (mixed cropping) from "scientific" monoculture. The characteristics of traditional polycultures that make them desirable were ignored by agricultural researchers in developing countries with the introduction of concept of green revolution into those countries. But recently, research concerning polycultures has blossomed and some of their benefits are becoming clear. Polyculture is the sustainable farming system prevailed in Sri Lanka for more 
than 2500 years. It has many sustainable characteristics such as diet diversity, diversified income generation, production stability, minimization of risk, low pest and diseases incidences, efficient use of labour, intensification of production with limited natural resources and maximization of returns under low levels of technology. These lessons the local people have learned through millennia of accumulated experience and survival are invaluable in designing modern development plans. Therefore, the policy makers should pay greater attention to indigenous knowledge in the development process at policy level. This is very important in preparing national agricultural policy for a country like Sri Lanka. The vast majority of the population in Sri Lanka is small scale farmers, each working less than two hectares of land. These farmers represent different ethnic groups. While remain invisible to policy makers these small farmers' groups work in a rather unorganized manner and search solutions for their "localized" farming problems through indigenous knowledge. Such technology is user-derived and tested through time. On the other hand, the critical strength of the indigenous knowledge is its ability to see the interrelation of disciplines, and then integrate them meaningfully. This holistic perspective and the resulting synergism show higher levels of developmental impact, adaptability and sustainability than Western modern knowledge. Therefore, it is a very good source of readily available and already tested appropriate technology for policy makers to use in their planning process.

The value of indigenous knowledge is not only limited to agriculture, environment and biodiversity. It has an immense value in education, medicine etc. Indigenous peoples' traditional model of education is a balanced and complementary model acceptable to the local community. It is an education system gradually developed from the accumulated knowledge of many generations. It leads to the development of a whole person in a dynamic family and community context. It incorporated principles of holism, integration, respect for the spiritual and natural world order, and the balance. On an individual scale, it encompassed total preparation of the total person for living a total life (Obomsawin, 1988). Later, some education experts have realized the value of holistic nature of the indigenous education systems and introduced the same into the modern education systems with a new title called "affective learning" (Eyford, 1990). The concept of affective learning is to follow a holistic approach to develop character, conscience, attitudes and moral values. According to Eyford (1990) the affective learning contains the forces that determine the nature of an individual's life and ultimately the life of an entire people. Neglect of affective learning has contributed to escalating crime, drug dependency, pornography, and family/social breakdown in the West (Eyford,1990).

While Western medical system mainly concentrates only one issue at a time the indigenous healing system (Aurvedic medicine) follows a holistic approach. It is interdisciplinary and combines knowledge of botany, toxicology, chemical physics, biochemistry, and psychology. Indigenous medical practitioners tackle prevention as well as therapy, perceiving illness and healing holistically. Therapies often enhance healing by treating the whole being, rather than targeting specific 
symptoms, and trace the disease to the context of the person's life, rather than a bacteria or virus. Exploration of plant medicines (ethno-pharmacology) has evolved over millennia to a current usage of some 20,000 species, which still form the major sources of medicine for the population of the majority of the world. Western science, in contrast, has fully studied only 1100 of Earth's 265,000 plants (of which some 40,000 have potential medical or nutritional value) (Obomsawin, 1988).

\section{Indigenous Knowledge in Sri Lanka}

Sri Lanka is rich in biodiversity as well as cultural diversity. It also has a long history. Therefore Sri Lanka is very rich in indigenous knowledge. According to traditional practice, agriculture in Sri Lanka was a community activity. Therefore, all the decisions related to agriculture were collective decisions taken by the community under the leadership of Gamarala (village chief). For example, farmers did not clear the forest for cultivation without obtaining the permission from Gamarala. Gamarala granted the permission only to newly married couple to clear the virgin forest for chena cultivation (Nawa Deli Hena). Other farmers had to provide strong justification in order to obtain the permission to clear a virgin forest for cultivation. Farmers used conservation farming techniques such as minimum tillage, mixed cropping, direct seeding mulching etc. wherever possible. Eco-friendly crop protection measures such as cultivation of a small portion of land to attract birds for pest management in paddy, performing kems, ritual or a religious rite and use of plants or plant extracts (botanicals) were practiced. Even today the practice of kems is common in certain rural areas of Sri Lanka. A kem is a kind of practice, technique or custom that is followed in order to obtain some favourable effect from a problem. Some kems combine the use of astrology with the use of certain plants or herbs. Other kems depend on the use of specific plants and mantras. These traditional practices have survived because they must be effective. If these had no real effect, they would have disappeared long ago. Some kems are based on careful observation of nature and natural phenomena. Irima Pideema (offering of milk rice) and Alu Saaththuwa (broadcasting of wood ash to the paddy field) to control leaf eating caterpillars in paddy fields are classic examples for the use of natural phenomena. Some kems are mechanical methods. Lighting of fire torches made of wrapping the sticks of trees such as Wara (Calatropis gigantea), Kaduru (Pagiantha dichotoma) or Gurulla (Leea indica) with a piece of saffron robe is a combination of mechanical method and botanicals. This is more than a ordinary light trap. The colour of the saffron robe and chemical properties of the selected sticks gives extra effect in pest control.

In addition to pest control, a classic example of the use of indigenous knowledge in Sri Lanka is the Bethama practice. Bethma is a practice that temporarily redistributes plots of land among shareholders (being paddy landowners) in part of the command area of a tank during drought periods. It is practiced when there is not enough water available to cultivate the entire command area.

\section{CONCLUSION}

It is very clear that there is much to be learned from the indigenous knowledge systems of local people. All the academics, policy makers, planers should pay greater attention to this 
invaluable treasure of knowledge that is threatened by extinction. If we are to move towards interactive technology development from the conventional transfer of technology approach we all may have to learn many things from our village level experts, the gurus of indigenous knowledge.

\section{References}

Appleton, H. (1993) Women: Invisible technologists Appropriate Technology 20(2): $1-5$.

Brouwers, J.H.A.M. (1993) Rural people's response to soil fertility decline: The Adja case (Benin), Wageningen Agricultural University Papers 93-4.

Ellen, R. and H. Harris (1996) Concepts of Indigenous Environmental Knowledge in Scientific and Development Studies Literature - A Critical Assessment. Draft Paper Presented at East-West Environmental Linkages Network workshop 3, Canterbury.

Eyford, G. (1990) Cultural dimensions of learning International Review of Education, UNESCO, Pp 197-200.

Fernandez, M.E. (1994) Gender and indigenous knowledge. Indigenous Knowledge \& Development Monitor 2: 6-7.

Flavier, J.M. (1995) The regional program for the promotion of indigenous knowledge in Asia In. D.M. Warren, L.J. Slikkerveer and D. Brokensha (Eds.) The Cultural Dimension of development: Indigenous Knowledge Systems. London, Intermediate Technology Publications. Pp 479-487.

Grenier, L. (1998) Working with Indigenous Knowledge - A Giude for Researchers, IDRC, Ottawa

Haverkort, B. and D.M. Millar (1994) Constructing diversity: The active role of rural people in maintaining and enhancing biodiversity. Etnoecologia 2: 51-63.

Larson, J. (1998) Perspectives on Indigenous Knowledge Systems in South Africa, World Bank Discussion Paper No. 3, Washington D.C., World Bank.

Mathias, E (1995) Framework for enhancing the use of indigenous knowledge, Indigenous Knowledge \& Development Monitor 3: 3-4.

Mishra, S. (1994) Women's indigenous knowledge of forest management in Orissa (India). Indigenous Knowledge \& Development Monitor 2: 3-5.

Obomsawin, R. (1988) First Nations Jurisdiction over Education, Assembly of First Nations, Ottawa,

Posey, D. A. (1995) Nature and indigenous guidelines for new Amazonian development strategies: Understanding biological diversity through etnoecology. In. J. Hemming (Eds.) Change in the Amazon Basin. Manchester, Manchester University Press. Pp 156-181.

Quiroz, C. (1996) Farmer experimentation in a Venezuelan Andean region. In. D.M. Warren, S. Fujiska and G Prain (Eds.) Indigenous Experimentation and Cultural Diversity. London, Intermediate Technology Publications. Pp 46-63.

Rajasekaran, B., D.M. Warren and S.C. Babu (1991) Indigenous natural-resource management systems for sustainable agricultural development - A global perspective Journal of International Development 3 (1): 1-15

Shiva, V. (1993) Monocultures of the Mind. Perspectives on Biodiversity and Biotechnology. London, Zed Books. 
Slikkerveer, L.J. (1989) Changing values and attitudes of social and natural scientists towards indigenous peoples and their knowledge systems. In. D.M. Warren, L.J. Slikkerveer and S.O. Titilola (Eds.) Indigenous Knowledge Systems: Implications for Agriculture and International Development, Studies in Technology and Social Change, No 11. Ames, Iowa State University. pp. 121137.

Warren, D.M. (1989) The impact of nineteenth century social science in establishing negative values and attitudes towards indigenous knowledge systems. In. D.M. Warren, L.J. Slikkerveer and S.O. Titilola (Eds.) Indigenous Knowledge Systems: Implications for Agriculture and International Development, Studies in Technology and Social Change, No 11. Ames, Iowa State University pp. 171-183.

Warren, D.M. (1991) Using Indigenous Knowledge in Agricultural Development. World Bank Discussion Papers No. 127. Washington, D.C. The World Bank.

Warren, D.M. and B. Rajasekaran (1993) Putting local knowledge to good use. International Agricultural Development 13 (4): 8-10. 